\title{
The Impact of the Coronavirus on the Short-term and Long-term of Chinese Infrastructure Industry
}

\author{
Zhao Chen ${ }^{1, *}$ Yuxin Zhou ${ }^{2}$ \\ ${ }^{1}$ Ridgefield High School, $700 \mathrm{~N}$ Salem Rd, Ridgefield, CT, 06877, United States \\ ${ }^{2}$ Hangzhou No.4 High School (International School), Hangzhou, Zhejiang 310018, China \\ *Corresponding author. Email: eiffelchen987@gmail.com
}

\begin{abstract}
In today's world, many countries are suffering from the epidemic caused by the coronavirus. In this case, China's construction projects will be delayed, which is caused by a series of factors, such as the characteristics of the industry itself and the quarantine policies. In order to further investigate the short-term and long-term effects of the epidemic on the industry, the author analyzed the characteristics of the industry and the requirements of the policies. Through literature research, it can be concluded that the output of the construction industry will decline in the short term, which will lead to financing difficulties; however, in the long run, the industry will operate smoothly in a larger market.
\end{abstract}

Keywords: Short term, Long term, Infrastructure, Financing.

\section{INTRODUCTION}

In early 2020, many Chinese people got infected from the coronavirus. In the meantime, in order to reduce the possibility of infection, the residents were not allowed to gather and must wear masks outdoors. During that period of the time, owing to the lack of places for patients, cities were planning to build emergency hospitals; in contrast, there were lots of problems need to be considered and overcome. At the same time, the construction projects were delayed due to the epidemic, which might be harmful to the economy such as the fiercer competition of living caused by housing. Hence, the research question addressed in this paper is how the traditional Chinese infrastructure industry develop in the short-term and long-term under this epidemic. This paper begins with the character of the industry itself, to show the hardness of the epidemic. Besides, by comparing the resumption policies, it is found that the virus not only influences the construction period, but also affects the cost of the business. Apart from that, the next section provides more specific analysis to demonstrate the effect of the epidemic from industry demand and other perspectives. The study is beneficial for the economy since it helps to accumulative experience: If the country in the same situation in the future, the government may have better policies to deal with such problems with shorter reaction time.

\section{ANALYSIS}

\subsection{Overview of the Epidemic Effect}

Compared with other industries, the characteristics of the construction industry determine that its epidemic prevention and control conditions are more complicated. As of midFebruary 2020, except for key projects, most of the construction projects are affected by factors such as the return of migrant workers and local resumption policies, and the resumption time is still delayed. Delayed resumption of work caused by the epidemic, restricted return of migrant workers, and local resumption policy requirements may drag down the progress of the project, which will greatly affect the output value and income of the construction industry in the first quarter. At the same time, measures such as personnel rework and isolation, procurement of epidemic prevention materials, enhanced daily monitoring as well as the shortage of raw materials caused by centralized construction after the epidemic is over, will cause the construction industry to face increased shortterm project cost. From a long-term perspective, 
due to factors such as the Spring Festival and winter construction conditions being restricted, the first quarter is the traditional off-season for construction. The affected projects can be compensated by rushing to work in subsequent quarters, and the output value of the construction industry throughout the year is expected to remain strong. Under the influence of pressure on real estate sales and the stagnant progress of bidding and contracting of infrastructure projects, the value of newly signed contracts in the construction industry in the first quarter will be greatly affected, but it will benefit from the subsequent increase in macro countercyclical adjustments and the release of special debt funds in advance. Put into use, the scale of infrastructure investment during the year is still expected to maintain a good growth trend, boosting the demand for the construction industry. The impact of the epidemic on the credit level of my country's construction industry and construction enterprises is limited, while market segments such as medical public buildings and prefabricated buildings are expected to usher in new market opportunities.

\subsection{The Difficulties of Resumption}

The construction industry has the characteristics of labor-intensive, many open-air operations, and the shift of production sites along with the location of the construction project. Compared with traditional manufacturing, it is more difficult to achieve standardized management in the construction industry due to the complexity of the epidemic prevention conditions in this industry. The situation in previous years is as follows: Most construction companies completed the construction of personnel and materials around the tenth day of the first lunar month. After the Lantern Festival, workers resumed work and proceeded with construction as scheduled. However, this year, affected by the epidemic, local governments have successively issued relevant requirements on the delay of resumption of work or new start time for construction companies after the Spring Festival. Most areas require companies to start construction no earlier than 24:00 on February 9, 2020, and enterprises in Hubei Province no earlier than 24:00 on the 13th. As a result, as of mid-February this year, most construction projects are still suspended affected by factors such as the return of migrant workers and local resumption policies, and the resumption time.
Migrant workers are the main force engaged in front-line work in China's construction industry. The National Bureau of Statistics "Monitoring and Survey Report on Migrant Workers in 2018" shows that in 2018 there were 53.63 million migrant workers in the construction industry in my country, accounting for $18.6 \%$ of the total migrant workers [1]. Meanwhile, rural migrant workers account for a relatively high proportion of migrant workers in China. In 2018, 172.66 million rural migrant workers went to work outside the township, accounting for $59.88 \%$ of the total rural migrant workers. Among them, 75.94 million went to work in other provinces [1]. For one thing, the Covid-19 epidemic has greatly reduced the number of migrant workers returning early. For another, due to the strict traffic control and the quarantine policy, the number of workers exporting across regions and provinces has been greatly reduced in a short time. In a state of shortage, the progress of the project will be dragged down, because the quarantine period accounts 7 to 14 days in most places. As a result, the personnel of some projects cannot back to work.

Regarding the resumption of work policy, due to the high concentration of construction site personnel, local housing and construction authorities have put forward stricter requirements for the prevention and control of construction site epidemics, such as closed centralized management of construction sites and living areas; increased health screening of laborers Inspection and personal protection; strengthen the sanitary inspection and disinfection of the construction site. Some places have proposed that once a confirmed case occurs in the project, it will be deemed a major safety accident (equivalent to the death of more than 10 people and less than 30 people), and the project will immediately stop and lock down the construction site, making construction companies more cautious in their decision to resume work. In addition, most places require construction sites to be equipped with adequate anti-epidemic control supplies such as masks and disinfectants. However, these supplies are currently in short supply. Therefore, the difficulty of material procurement also hindered the recovery of the project.

While preventing and controlling the epidemic, the state is also actively promoting the resumption of work and production of enterprises, striving to ensure the smooth operation of the economy. The Ministry of Transport issued a notice on February 8 that except for Hubei Province and other areas where the epidemic prevention and control tasks are 
heavy, if the weather conditions meet the construction requirements, in principle, preparations for the resumption of work should be made before February 15, 2020, and strive to February 20 work has resumed a few days ago; Liaoning, Shandong, Sichuan and other places have also pointed out in relevant policies that they will speed up the construction of key projects while controlling the epidemic [2]. On the whole, railways, rail transit, highways, and other key livelihood projects are expected to resume work as a priority in late February. The resumption of housing construction projects will lag slightly behind, but it is expected to resume work from the end of February to early March. The impact of the epidemic on construction delays is expected to be around 20 to 30 days, which will have a greater impact on the output value and income of the construction industry in the first quarter.

In addition to having a greater impact on the construction period, the epidemic may also increase the cost of construction companies to a certain extent. Firstly, measures such as personnel rework and isolation, procurement of epidemic prevention materials, and enhanced daily monitoring and monitoring will lead to increased costs; aside from this, the concentrated start of construction after the end of the epidemic may make the supply of upstream construction materials and machinery equipment tighter, superimposing "labor shortage" Problems, or will raise the cost of the project.

\subsection{Methods Published by the Local and Effect on Consumption and Net Exports}

In order to cope with the adverse effects of the above factors on the construction industry, various places have actively introduced relevant measures. Cities such as Zhengzhou and Qingdao have issued policy implementation opinions, suggesting that the cost of epidemic prevention should be included in the project cost and be added in full; Department of Housing and Urban-Rural Development in Zhejiang issued The "Notice on Doing a Good Job in the Prevention and Control of the Epidemic to Support the Development of Enterprises" states that major changes in the prices of labor and materials caused by the prevention and control of the epidemic, and the corresponding adjustment method is not agreed in the contract, can be based on the actual situation according to the "manual and less than 5\%" The price risk of individual materials shall be borne by the contractor, and the excess part shall be borne by the contracting party". Economic growth has been greatly impacted by the new crown pneumonia epidemic, and it is not realistic that consumption will rebound quarterly, and investment is expected to stabilize growth. In the troika of economic growth, both consumption and exports have been more severely impacted by the new crown pneumonia epidemic. In terms of consumption, according to the National Bureau of Statistics announced on March 16, affected by the epidemic, the total retail sales of consumer goods from January to February 2020 was 5,213 billion yuan, a year-on-year decrease of $20.5 \%$. The absolute retail sales of consumer goods other than automobiles were $4,847.6$ billion yuan. A year-on-year decrease of $18.9 \%$, of which catering was the most affected. From January to February 2020, national catering revenue was 419.4 billion yuan, a year-on-year decrease of $43.1 \%$ [3]. According to a report issued by the China Cuisine Association on February 21, during the epidemic, $93 \%$ of catering companies chose to close their stores, $78 \%$ of catering companies lost more than $100 \%$ of their operating income, and consumption, led by the catering industry, suffered severe losses due to the epidemic [4]. The catering, tourism, and retail industries that have been greatly affected by the epidemic are limited by the flow of people on a single day. The consumption growth after the epidemic is over cannot make up for the losses during the suspension period. With reference to the consumption curve after the end of the SARS epidemic, there is a high probability that consumer demand in the second quarter will recover as the epidemic subsides. The decline in consumption in the first quarter will not be able to be filled by subsequent surges in consumption. In terms of exports, according to statistics from China Customs, affected by the epidemic, the total value of imported goods from January to February 2020 was US\$299.544 billion, a year-on-year decrease of $4 \%$, and the total value of exports was US\$292.449 billion, a year-on-year decrease of $17.2 \%$. Material processing trade and border small-scale trade were greatly affected by the epidemic. The export value was USD $7,280.95 / 294.42$ billion, a year-on-year decrease of $22.7 \% / 20.6 \%$ [5]. The impact of the epidemic has caused damage to the consumption and export carriages. In the short term, the investment will become a key factor in economic growth and play a role in stabilizing growth. 


\subsection{Influences by the Epidemic from Several Aspects}

From the perspective of industry demand, the epidemic will have a greater impact on the current nationwide real estate sales in the short term. In particular, third- and fourth-tier cities have missed the return home purchase window period around the Spring Festival. The start of the project has weakened, and the pressure of payment may be transmitted to the housing construction industry chain. Construction companies that focus on housing construction may also face the risk of project payment recovery; in the field of infrastructure, the work of governments at all levels in the short term will focus on the epidemic for prevention and control, the progress of bidding and contracting of new infrastructure projects may be affected to a certain extent; in addition, since most manufacturing production has been affected by the epidemic, related engineering construction investment may also be delayed. On the whole, the superposition of the above factors will greatly negatively affect the amount of newly signed construction contracts in the first quarter of 2020, and the credit risk faced by small and mediumsized construction companies with tight short-term funds will be amplified.

In the medium and long term, the epidemic will not have a fundamental impact on subsequent real estate investment and development, and it will have a limited impact on the prosperity of the downstream housing construction industry. However, the real estate market in some cities with more severe epidemics may be greatly impacted. The impact of the internal construction industry is worthy of attention; this epidemic reflects a certain shortcoming in the domestic medical and health infrastructure field. Later, the construction and layout planning of hospitals and emergency medical places in various places may be strengthened, which is conducive to the development of the medical public construction field.

In terms of infrastructure, due to the greater impact of the epidemic on the economy in the first quarter, the full realization of the goal of a well-off society in 2020 will require a counter-cyclical adjustment to infrastructure investment. On February 3, the Politburo meeting emphasized that "to continue to achieve this year's economic and social development goals and tasks are working hard", "doing a good job of "six stability", "increase the start of new investment projects and actively promote projects under construction" [6]. It is expected that infrastructure investment will become an important engine for stable economic growth during the year. The infrastructure construction market is relatively optimistic. From a funding point of view, in order to stabilize market expectations and boost market confidence, the central bank maintained reasonable and sufficient liquidity through large-scale reverse repurchase operations after the holiday, laying a foundation for the subsequent reduction of LPR and conducive to subsequent project construction funds and financing package.

The special debt quota, issued by the Ministry of Finance, reached 290 billion yuan in advance on February 11. The cumulative special debt quota issued in advance in 2020 has reached 1.29 trillion yuan, which has reached the upper limit of the authorized quota obtained by the State Council. Moreover, a total of 714.8 billion yuan of special bonds were issued in January 2020, which is 4.63 times that of the same period in 2019, which is the highest value of monthly issuance since 2018[6]. Under the condition that construction funds are fully in place, within the year Infrastructure investment is still expected to achieve steady growth. In the medium and long term, the epidemic will not have a major impact on the credit level of the domestic construction industry.

\section{CONCLUSION}

In conclusion, considering the delayed resumption of work caused by the epidemic, restrictions on the return of migrant workers, and local resumption policies, the output value and income of the construction industry in the first quarter will be greatly affected. Construction projects in areas with severe epidemics and poorly managed sites may face longer work stoppages, the implementation of on-site prevention and control measures in the short term, the shortage of engineering materials after centralized construction, and the "labor shortage" may cause a further increase in management difficulty and increase in costs, and pressure on real estate sales to pay back. In addition, the credit risk faced by small and medium-sized construction companies that are transmitted to the housing construction industry chain or that cause short-term funding is relatively tight. In the medium and long term, under the requirement to play the role of investment stabilizing growth, the current policy and financial benefits can provide strong support for the smooth 
operation of the construction industry. Furthermore, the impact of the epidemic on the credit level of China's construction industry and construction enterprises is limited, and market segments such as medical public buildings and prefabricated buildings are expected to usher in new market opportunities.

\section{AUTHORS' CONTRIBUTIONS}

Zhao Chen chose the topic of this paper, did the research and wrote the manuscript. Yuxin Zhou modified the manuscript and improved the expressions as well as completed some details in the manuscript by discussing with the first author.

\section{REFERENCES}

[1] Finance.sina.com.cn. 2019. 2018 migrant workers monitoring survey report released: average monthly wages increased by $6.8 \%$. [online] Available at: <https://finance.sina.com.cn/roll/2019-0429/doc-ihvhiqax5763329.shtml> [Accessed 29 January 2021].

[2] Gov.cn. 2020. The latest news on epidemic prevention and control on February 8! _State Council News. China Government Network. [online] Available at: <http://www.gov.cn/guowuyuan/202002/09/content_5476318.htm> [Accessed 29 January 2021].

[3] Stats.gov.cn. 2020. From January to February 2020 , total retail sales of consumer goods will drop by $20.5 \%$. [online] Available at: <http://www.stats.gov.cn/tjsj/zxfb/202003/t20 200316_1732236.html> [Accessed 29 January 2021].

[4] Www2.deloitte.com. 2020. [online] Available at:

<https://www2.deloitte.com/content/dam/Delo itte/global/Documents/About-

Deloitte/COVID-19/gx-covid-19-impact-onfinance-operations-in-the-chinese-cateringindustry.pdf> [Accessed 29 January 2021].

[5] Gov.cn. 2020. The State Council Information Office holds a press conference on the import and export situation in the first half of 2020_press release. China government website. [online] Available at: $<$ http://www.gov.cn/xinwen/2020- 07/14/content_5526721.htm> [Accessed 29 January 2021].

[6] Finance.sina.cn. 2020. Dagong International: The impact of the epidemic on the infrastructure business of the urban investment industry in 2020 is limited. [online] Available at: <https://finance.sina.cn/bond/zsyj/2020-0228/detail-iimxxstf5091605.d.html> [Accessed 29 January 2021]. 